\title{
THE
}

\section{Environmental Application of Cyclodextrin Metal-Organic Frameworks in an Undergraduate Teaching Laboratory}

\author{
Daniel R. Jones \\ University of Rhode Island \\ Dana J. DiScenza \\ University of Rhode Island \\ Teresa L. Mako \\ University of Rhode Island \\ Mindy Levine \\ University of Rhode Island, m_levine@uri.edu
}

Follow this and additional works at: https://digitalcommons.uri.edu/chm_facpubs

The University of Rhode Island Faculty have made this article openly available.

Please let us know how Open Access to this research benefits you.

This is a pre-publication author manuscript of the final, published article.

Terms of Use

This article is made available under the terms and conditions applicable towards Open Access

Policy Articles, as set forth in our Terms of Use.

\section{Citation/Publisher Attribution}

Jones, D. R., DiScenza, D. J., Mako, T. L., \& Levine, M. (2018). Environmental Application of Cyclodextrin Metal-Organic Frameworks in an Undergraduate Teaching Laboratory. J. Chem. Educ. 95(9), 1636-1641. doi: 10.1021/acs.jchemed.8b00357

Available at: http://dx.doi.org/10.1021/acs.jchemed.8b00357 
TITLE Environmental Application of Cyclodextrin Metal-Organic Frameworks in an Undergraduate Teaching Laboratory

AUTHORS Daniel R. Jones, ${ }^{1 *}$ Dana J. DiScenza, ${ }^{1 *}$ Teresa L. Mako,${ }^{1}$ and Mindy Levine ${ }^{1}$

${ }^{1}$ Department of Chemistry, University of Rhode Island, 140 Flagg Road, Kingston, RI 02881; email: mindy.levine@gmail.com; mlevine@chm.uri.edu; tel: 401-874-4243; fax: 401-874-5072

* These authors contributed equally to this work

KEYWORDS: Environmental Chemistry, Interdisciplinary/Multidisciplinary, Upper-Division Undergraduate, Laboratory Instruction, Hands-On Learning/Manipulatives, UV-Visible Spectroscopy

\begin{abstract}
Reported herein is a multi-disciplinary laboratory experiment for advanced undergraduate students that includes elements of material synthesis, in the synthesis of cyclodextrin-containing metal-organic frameworks (CD-MOFs), and environmental chemistry, in the use of these MOFs for pollutant removal. This multi-day laboratory experiment starts with the synthesis of cyclodextrin-containing metal-organic frameworks (CD-MOFs) using vapor diffusion crystal growth procedures, followed by the use of the CDMOFs for a pollutant removal application. Specifically, the CD-MOFs were used for the removal of a methylene blue dye (a common mimic of aromatic pollutants) from an organic solution, with the monitoring of the success of the removal procedures using UV-visible spectroscopy. This experiment was implemented as part of a larger multi-day unit, and undergraduate students were particularly engaged with and excited by the CD-MOF synthesis and methylene blue removal experimental modules. As a result, the decision was made to make these two components a stand-alone multi-disciplinary laboratory experiment, the results of which are reported herein.
\end{abstract}

\title{
INTRODUCTION
}

Anthropogenic (i.e. man-made) environmental disasters include the 2010 Deepwater Horizon oil spill, which led to the release of approximately 4.9 million barrels of oil into the Gulf of Mexico; ${ }^{1}$ the 2014 Elk River chemical spill, which contaminated the water supply of the Charleston, West Virginia metropolitan area and affected approximately 300,000 residents; ${ }^{2}$ and the Love Canal landfill incident, which refers to a 70 -acre landfill filled with toxic chemicals that affected residents of the Niagara Falls, New York area. ${ }^{3}$ Methods to remediate such disasters and/or mitigate their environmental and public health impacts include physical removal of the contaminants, which is limited to cases in which the contaminant can be easily isolated; ${ }^{4,5}$ chemical treatment procedures, such as in the 2014 Elk River spill; ${ }^{6}$ and a mixture of chemical and physical remediation procedures, such as in the Deepwater Horizon ${ }^{7}$ and other oil spill cleanup efforts. ${ }^{8}$

Although the development of novel environmental remediation strategies and analysis of the efficacy of these strategies are both highly active areas of research, ${ }^{9-11}$ they are included only rarely in the undergraduate chemistry curriculum, and even more rarely in a hands-on laboratory setting. ${ }^{12}$ This is a missed pedagogical opportunity, as research indicates that the vast majority of undergraduate students in the United States are aware of the aforementioned harmful anthropogenic incidents, ${ }^{13-15}$ and additional research indicates that using real-world examples that are familiar to students improves student learning, retention, and engagement in the classroom setting. ${ }^{16,17}$ In fact, the majority of undergraduate chemistry teaching continues to be segregated by traditional disciplines (organic, inorganic, physical, and analytical). Although increasing numbers of departments include environmental chemistry in their formal curriculum, ${ }^{18}$ there continues to be a need to incorporate more environmental chemistry-focused laboratories. ${ }^{19,20}$ An additional problem associated with discipline-segregated curricula is the lack of interdisciplinary education. Because much of the scientific research enterprise is interdisciplinary, ${ }^{21}$ adequate preparation of undergraduate students for future employment in the chemical enterprise should focus on delivering relevant curricular material. ${ }^{22}$ Although efforts to incorporate more interdisciplinary lessons have been 
reported by this journal ${ }^{23-25}$ and others, ${ }^{26,27}$ the vast majority of the undergraduate curriculum is still not interdisciplinary.

Senior-level undergraduate laboratory classes for chemistry majors provide a unique opportunity to implement laboratory curricula focused on issues beyond the four traditional disciplines, including interdisciplinary experiments with an environmental focus. Previous reports from our group have detailed the implementation of two new experiments in such an advanced laboratory setting: the synthesis and photophysical characterization of a near-infrared emitting squaraine dye, ${ }^{28}$ and the synthesis, characterization, and thin film fabrication of a highly fluorescent conjugated polymer. ${ }^{29}$ Both of these multiday experiments start with a synthetic organic chemistry component, followed by analysis of the newly obtained organic product. The interdisciplinary components of these experiments include photophysical analyses of the products (for both the squaraine and the polymer), incorporation of the polymer into thin films and nanoparticles, and analysis of how aggregation due to different polymer presentations/manifestations affect the resultant photophysical properties.

Reported herein is an additional interdisciplinary experiment that we have designed, implemented, and evaluated in the undergraduate teaching laboratory. Like the previously reported experiments from our group, this experiment starts with a synthetic component, the synthesis of cyclodextrin-containing metalorganic frameworks (CD-MOFs) via vapor diffusion crystal growth (Figure 1). Such CD-MOF architectures were first reported in $2010,{ }^{30}$ with a key benefit of the CD-MOF system that it was derived from food products. The first report of the use of CD-MOFs for carbon dioxide capture was in $2011 .{ }^{31}$ Since then, they have been reported extensively in the literature for environmental, ${ }^{32}$ medicinal, ${ }^{33}$ and catalytic ${ }^{34}$ applications. There is also a single report of an undergraduate laboratory experiment using CD-MOFs, ${ }^{35}$ although that experiment focused on the synthesis of the CD-MOFs and their use in carbon dioxide capture exclusively, leaving many other applications of these materials unexplored. After the synthetic component of CD-MOF fabrication was completed, material characterization was carried out by trained laboratory technicians, using highly specialized equipment.

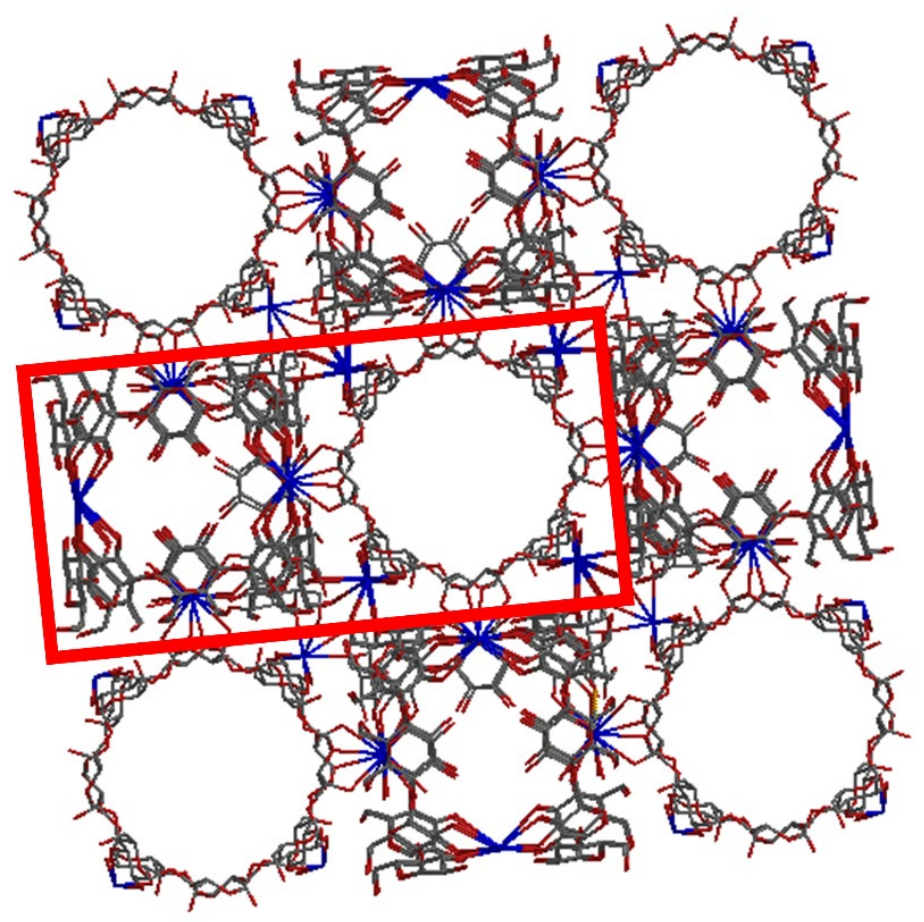

Figure 1: Computational model of a $\gamma$-cyclodextrin-containing MOF generated using Spartan 10 software, with $\mathrm{K}^{+}$colored in blue ${ }^{35}$. The red box highlights the repeating unit of the CD-MOF structure. 
Following the successful completion of the synthesis (by the students) and analysis (by laboratory technicians), students used their newly synthesized MOFs for the removal of methylene blue dye from solution, with the success of the removal monitored using UV-visible spectroscopy. Methylene blue has been extensively reported in the literature as a small-molecule mimic of aromatic organic pollutants, ${ }^{36-38}$ as well as a pharmaceutically active agent, ${ }^{39}$ and its well-characterized absorption spectra provides a straightforward way to monitor the success of its removal. Additionally, students were able to see a visual color change of the solution as the CD-MOFs removed the methylene blue from solution, with the blue solution changing to a colorless one as the methylene blue removal progressed (vide infra).

The synthesis and environmental remediation applications of CD-MOFs were tested as part of a larger multi-day experiment in the Fall 2016 and Fall 2017 semesters, with 100\% of the students over the two years (13 total students) able to successfully remove methylene blue from solution using the material they had synthesized. Moreover, feedback from the students on these aspects of the multi-day experiment was uniformly positive, and included the following statements, "I liked how this experiment combined synthetic organic chemistry with environmental analytical chemistry," and, "I liked how this experiment had an environmental application. Environmental remediation is an important topic to me, so this was my favorite laboratory experiment all semester." As a result, the decision was made to make these components a standalone laboratory experiment.

Key learning objectives at this stage in the undergraduate students' educational experience included the development of an awareness of interdisciplinary chemistry, and a particular focus on the use of chemistry for environmental remediation. Success in achieving these objectives was measured through the positive feedback from the students and through the students' success in using a material they synthesized for the removal of methylene blue from the organic solution.

\section{EXPERIMENTAL PROCEDURES}

\section{Materials and Methods.}

All chemicals were received from Sigma-Aldrich or from Fisher Scientific and were used as received. UVVisible spectroscopy was performed on a Shimadzu UV 3600 plus instrument. NMR spectra were acquired using a Bruker Ascend $400 \mathrm{MHz}$ spectrometer. XRD analysis was performed with a Rigaku Ultima IV instrument. All SEM images were obtained on a Zeiss Sigma VP microscope.

\section{MOF Synthesis.}

The procedure for the synthesis of CD-MOFs followed literature-reported procedures, ${ }^{35}$ and included vapor diffusion crystal growth by adding acetone to an aqueous solution containing $\gamma$-cyclodextrin and potassium hydroxide, followed by washing crystals with DCM and then drying in an oven. The presence of the desired CD-MOF crystals was inferred by the formation of a solid precipitate following the vapor diffusion crystal growth procedure.

\section{MOF Characterization.}

Extensive characterization and subsequent detailed confirmation of the presence of CD-MOFs was complicated by the practical limitations of performing solid-state characterization experiments with undergraduate students, especially using advanced instrumental techniques. As such, trained technicians conducted the characterization experiments using representative student samples.

\section{Pollutant Removal.}

The ability of the MOFs to remove pollutants from solution was demonstrated by removing methylene blue (as a mimic of organic pollutants) from a DMSO solution, with the success of the dye removal monitored using UV-visible spectroscopy (see Electronic Supporting Information (ESI) for full experimental details).

\section{HAZARDS}


Personal protective equipment, including laboratory gloves, goggles, and coats should be worn throughout the experiment. Potassium hydroxide is an irritant to the skin and eyes and is harmful if inhaled or swallowed. Acetone is an irritant to the skin, eyes, and respiratory system. Dichloromethane (DCM) is a human carcinogen and possible mutagen, and is also an irritant to the skin, eyes, and respiratory system. Inhaling DCM can cause drowsiness and dizziness. Dimethyl sulfoxide (DMSO) is an irritant to the skin, eyes, and respiratory system. Methylene blue is an irritant to the skin, eyes, and respiratory system and is harmful if swallowed. NMR instruments produce a strong magnetic field and people with pacemakers are advised to consult with their physician before entering a room where an NMR spectrometer is located.

\section{RESULTS AND DISCUSSION}

$100 \%$ of the students enrolled in the Advanced Organic Chemistry Laboratory over a two-year time period observed the formation of a visible precipitate from mixing $\gamma$-cyclodextrin with a potassium hydroxide solution and allowing vapor diffusion between the solvents over a two-day time period to facilitate crystal growth. For many of the students, this was their first introduction to the use of vapor diffusion for crystal growth, which is an experimental technique with applications beyond this particular laboratory module. ${ }^{40}$ Two examples of the visible solids formed via this procedure are shown in Figure 2.

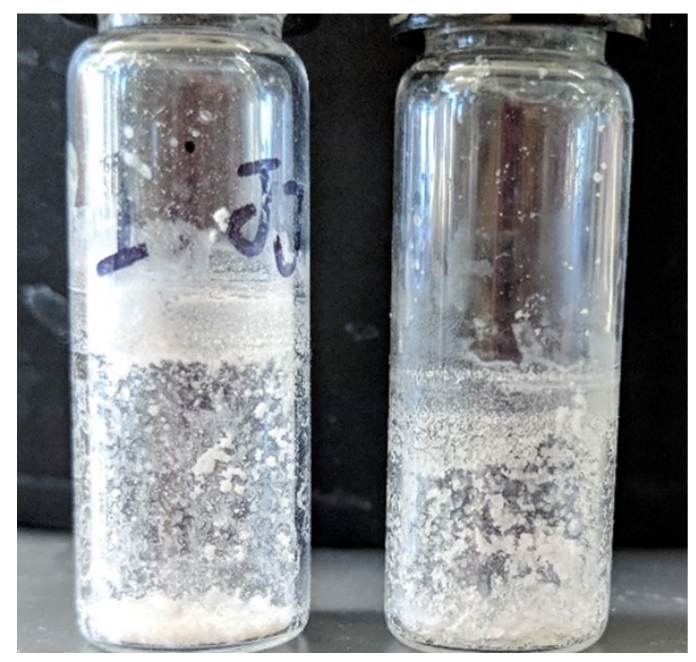

Figure 2: Examples of cyclodextrin-MOF solids made by two different students, after a 7-day crystallization period, followed by multiple washes with dichloromethane and oven drying of the samples

Confirmation of the successful synthesis of a CD-MOF was provided by single-crystal X-ray analysis of one student's sample conducted by Dr. Peter Mueller at MIT (see ESI for crystal structure details). Other support for the formation of a CD-MOF came from a scanning electron microscopy (SEM) image of a representative student sample, showing a highly cubic structure with visible similarities to other cyclodextrin-MOF structures that have been characterized by $\mathrm{SEM} ;{ }^{41}$ and a powder X-ray diffraction (XRD) spectrum of another representative sample, showing high crystallinity in accordance with literaturereported XRD spectra of analogous compounds (see ESI for more details). ${ }^{42}$ These experiments were conducted by trained technicians, because the costly instrumentation was not available for undergraduate students, and the overall goal of the experiment was focused on the environmental application of CD-MOFs in pollutant removal procedures.

The next part of the cyclodextrin-MOF experiment was to use the MOFs to remove an organic dye, methylene blue, from a solution, and to monitor this removal using UV-visible spectroscopy. Methylene blue has been reported in the literature as a model compound for organic pollutants, ${ }^{43}$ and its high extinction coefficient provides a sensitive way to monitor the success of its removal, as even small changes in the concentration of methylene blue will result in noticeable absorption changes. An approximately $20 \mathrm{mg}$ sample of cyclodextrin-MOFs adsorbed an average of $0.0078 \mu \mathrm{mol}$ of methylene blue from the solution 
over a time period of one hour, with the concentration calculated based on the known extinction coefficient of methylene blue using the Beer-Lambert relationship. ${ }^{44}$ This adsorption was visible to the naked eye as the color of the solution changed from blue to colorless (Figure 3A), and resulted in a substantial decrease in the intensity of the UV-visible absorption spectrum of the solution (Figure 3B).
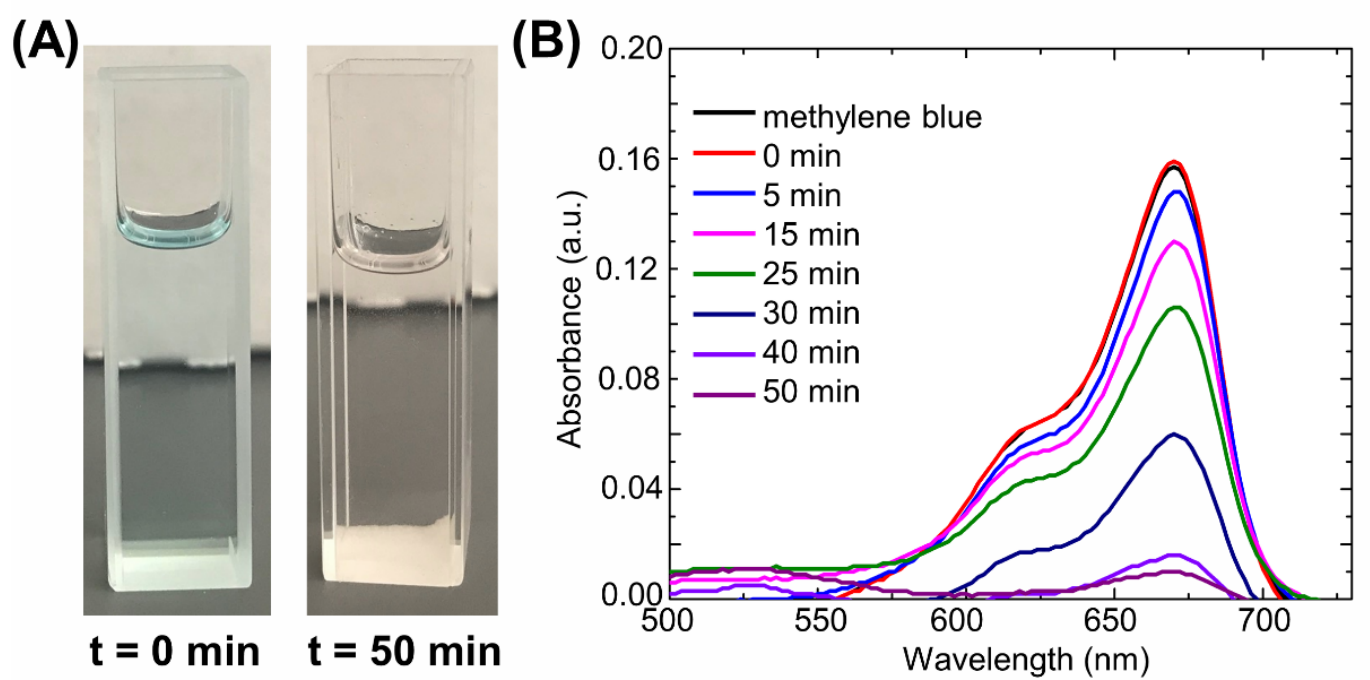

Figure 3. (A) Visible color change in methylene blue solution from time $=0$ minutes to time $=50$ minutes; and (B) Accompanying changes in the UV-visible absorption spectrum showing a decrease in the intensity of absorption

Explaining to students how the CD-MOF was able to remove methylene blue from the solution required a discussion of the supramolecular complexation properties of cyclodextrin, and in particular its ability to bind small molecule organic guests in its interior. ${ }^{45}$ Although hydrophobically-driven host-guest complexation is well-studied in supramolecular chemistry research, ${ }^{46}$ it is rarely introduced in the undergraduate setting, with isolated reports of the hydrophobic effect in three-dimensional protein structures ${ }^{47}$ and supramolecular complexation reported. ${ }^{48}$ To further understand the interaction of a cyclodextrin host with methylene blue, therefore, one-dimensional ${ }^{1} \mathrm{H}$ NMR spectra of $\gamma$-cyclodextrin and methylene blue were provided to students. Additionally, students measured a two-dimensional NMR spectrum of a methylene blue guest bound in a $\gamma$-cyclodextrin host (not in a MOF structure, because MOFs cannot be analyzed via solution-state NMR spectroscopy), with the spectrum from one of the student samples shown in Figure $4 .{ }^{49}$ 


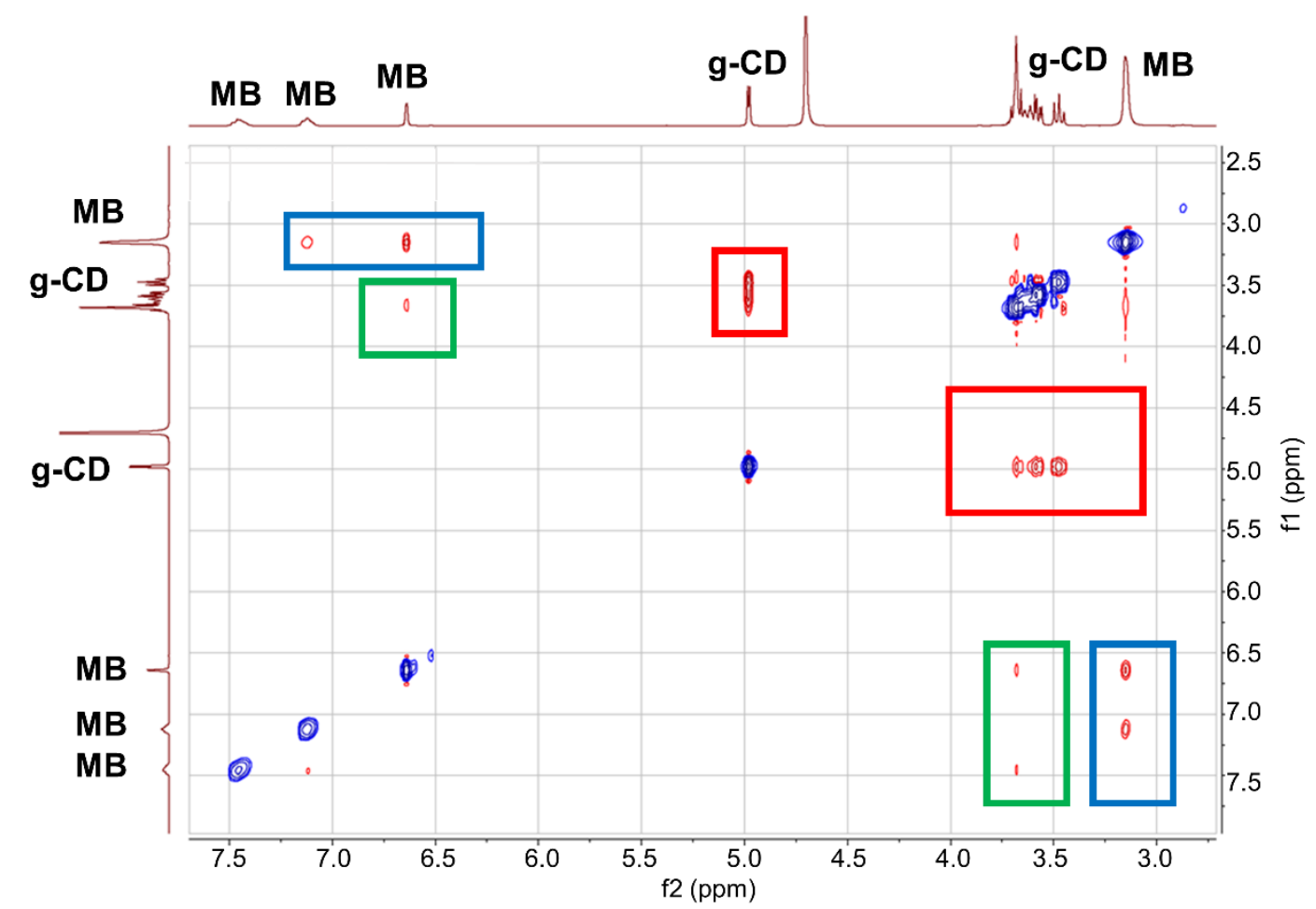

Figure 4: Example of student-acquired two-dimensional ROESY spectrum of a methylene blue dye bound in a $\gamma$-cyclodextrin host in $\mathrm{D}_{2} \mathrm{O}$, with cross peaks indicating through-space interactions shown in the blue boxes (methylene blue interacting with itself), green boxes (methylene blue interacting with the cyclodextrin host), and red boxes ( $\gamma$-cyclodextrin interacting with itself); $(\mathrm{MB}=$ methylene blue; $g-\mathrm{CD}=$ $\gamma$-cyclodextrin)

This ROESY spectrum of the solution-state complex provided cross-peaks that indicated through-space interactions. In particular, the spectrum shows seven prominent cross-peak areas: two of which show the coupling between the methyl amine protons and the two closest aromatic protons on methylene blue, highlighted in blue in Figure 4, indicating through-space coupling of different segments of the methylene blue structure. The other two most prominent peaks highlighted in green in Figure 4, show through-space interaction peaks between the aromatic protons of methylene blue and the major peak that represents $\gamma$ cyclodextrin protons. The other three prominent peaks highlighted in red in Figure 4, indicate throughspace interactions of $\gamma$-cyclodextrin with itself. Although substantial instruction was required for students to understand and interpret the ROESY spectrum successfully, the pedagogical opportunities provided through such instruction was significant. In particular, students learned how to measure through-space interactions that occur between the methylene blue guest and the $\gamma$-cyclodextrin host, which in turn leads to a better understanding of how a CD-MOF can facilitate the removal of the methylene blue pollutant from the DMSO solution in the environmental remediation component.

\section{CONCLUSIONS}

The design and implementation of a multi-disciplinary laboratory experiment in the synthesis and environmental applications of cyclodextrin-containing metal organic frameworks (CD-MOFs) was successfully executed in URI's advanced organic laboratory class for two consecutive years. CD-MOFs were synthesized by students using vapor diffusion crystal growth and analyzed by technicians to confirm successful synthesis. CD-MOFs were then used to remove methylene blue from a solution to simulate pollutant removal applications. $100 \%$ of students gave positive feedback about the combination of synthetic 
organic chemistry and environmental analytical chemistry in this multi-day laboratory experiment, and indicated a strong likelihood that the educational content would be useful in the next phases of their careers.

The students in the study were part of an advanced organic laboratory, but the multidisciplinary nature of this project makes it a suitable project for other advanced laboratories in environmental and analytical chemistry. Moreover, we note that this experiment complements our previously published laboratory experiments in this journal in the synthesis and analysis of near-infrared squaraine fluorophores and of fluorescent organic polymers, ${ }^{28,29}$ in that these three experiments, in conjunction with any of the numerous material science laboratory experiments published in this journal, ${ }^{50-52}$ can be used as the basis for a semester-long laboratory course on materials chemistry.

\section{ACKNOWLEDGEMENTS}

We gratefully acknowledge the assistance of Research Professor Everett Crisman for his assistance with the SEM and XRD measurements.

\section{ASSOCIATED CONTENT}

Materials and methods; Laboratory schedule; Student handouts; Laboratory report guidelines; Instructor notes; Student spectra (DOCX, PDF).

\section{TABLE OF CONTENTS GRAPHIC}
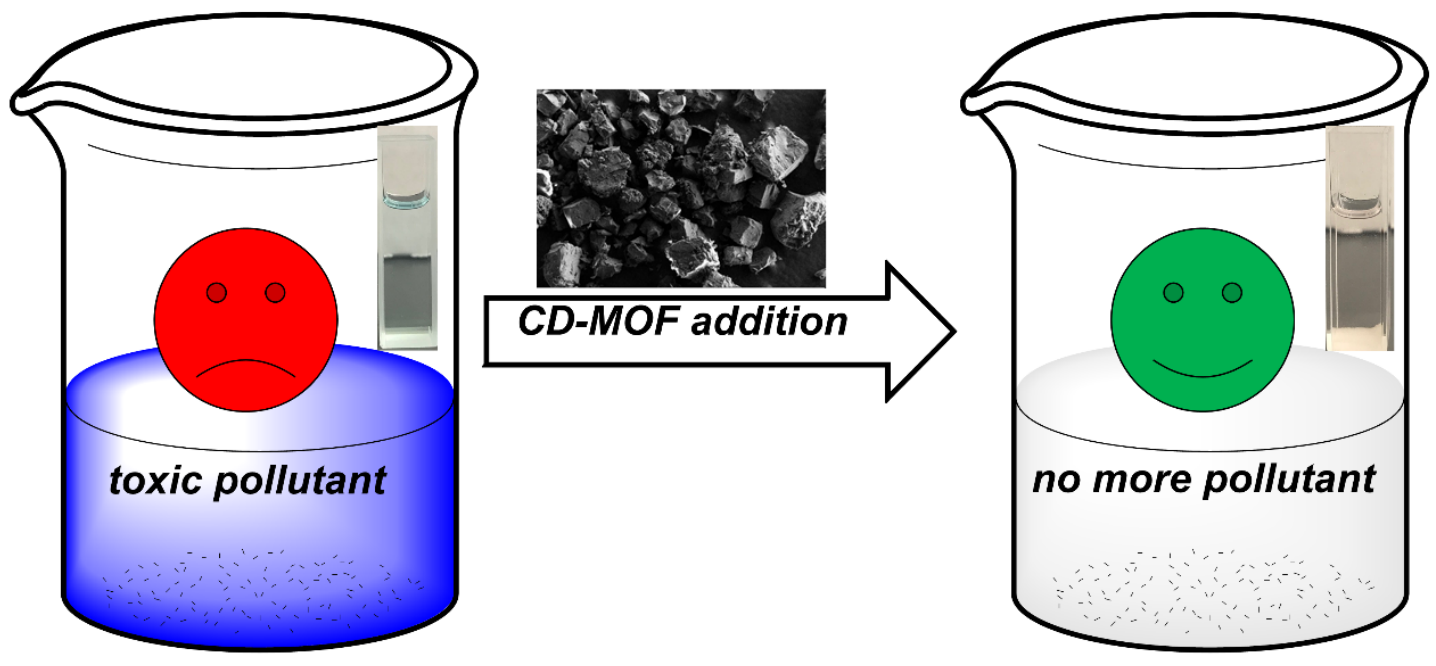

\section{REFERENCES}

${ }^{1}$ McNutt, M. K.; Chu, S.; Lubchenco, J.; Hunter, T.; Dreyfus, G.; Murawski, S. A.; Kennedy, D. M. Applications of Science and Engineering to Quantify and Control the Deepwater Horizon Oil Spill. Proc. Natl. Acad. Sci. U.S.A. 2012, 109, 20222-20228.

${ }^{2}$ Stolze, L.; Volpin, F. Modeling of the Elk River Spill 2014. Environ. Sci. Pollution Res. 2015, 22, 79807985.

${ }^{3}$ Vianna, N. J. The Love Canal: Issues and Problems. Chemosphere 1983, 12, 705-712.

${ }^{4}$ Ragab, D.; Gomaa, H. G.; Sabouni, R.; Salem, M.; Ren, M.; Zhu, J. Micropollutants Removal from Water Using Microfiltration Membrane Modified with ZIF-8 Metal Organic Frameworks (MOFs). Chem. Engineering J. 2016, 300, 273-279. 
${ }^{5}$ Magri, D.; Caputo, G.; Perotto, G.; Scarpellini, A.; Colusso, E.; Drago, F.; Martucci, A.; Athanassiou, A.;
Fragouli, D. Titanate Fibroin Nanocomposites: A Novel Approach for the Removal of Heavy-Metal Ions from Water. ACS Appl. Mater. Interfaces 2018, 10, 651-659.

${ }^{6}$ Whelton, A. J.; McMillan, L.; Connell, M.; Kelley, K. M.; Gill, J.P.; White, K. D.; Gupta, R.; Dey, R.; Novy, C. Residential Tap Water Contamination Following the Freedom Industries Chemical Spill: Perceptions, Water Quality, and Health Impacts. Environ. Sci. Technol. 2015, 49, 813-823.

${ }^{7}$ Nyankson, E.; Rodene, D.; Gupta, R. B. Advancements in Crude Oil Spill Remediation Research After the Deepwater Horizon Oil Spill. Water Air Soil Pollution 2016, 227, 1-22.

${ }^{8}$ Yim, U. H.; Kim, M.; Ha, S. Y.; Kim, S.; Shim, W. J. Oil Spill Environmental Forensics: the Hebei Spirit Oil Spill Case. Environ. Sci. Technol. 2012, 46, 6431-6437.

${ }^{9}$ Muya, F. N.; Sunday, C. E.; Baker, P.; Iwuoha, E. Environmental Remediation of Heavy Metal Ions from Aqueous Solution Through Hydrogel Adsorption: A Critical Review. Water Sci. Technol. 2016, 73, 983992.

${ }^{10}$ Lyu, H.; Gao, B.; He, F.; Ding, C.; Tang, J.; Crittenden, J. C. Ball-Milled Carbon Nanomaterials for Energy and Environmental Applications. ACS Sustainable Chem. Engineering 2017, 5, 9568-9585.

${ }^{11}$ Liu, X.; Zhou, Y.; Zhang, J.; Tang, L.; Luo, L.; Zeng, G. Iron Containing Metal-Organic Frameworks: Structure, Synthesis, and Applications in Environmental Remediation. ACS Appl. Mater. Interfaces 2017, 9, 20255-20275.

12 Fernandez-Calvino, D.; Perez-Rodriguez, P.; Novoa-Munoz, J. C.; Estevez, M. A. Is the Total Concentration of a Heavy Metal in Soil a Suitable Tool for Assessing the Environmental Risk? Considering the Case of Copper. J. Chem. Educ. 2017, 94, 1133-1136.

${ }^{13}$ Thomas, T. L.; Kannaley, K.; Friedman, D. B.; Tanner, A. H.; Brandt, H. M.; Spencer S. M. Media Coverage of the 2014 West Virginia Elk River Chemical Spill: A Mixed-Methods Study Examining News Coverage of a Public Health Disaster. Science Commun. 2016, 38, 574-600.

${ }^{14}$ Ostman, R. E.; Parker, J. L. Impact of Education, Age, Newspapers, and Television on Environmental Knowledge, Concerns, and Behaviors. Environ. Education 1987, 19, 3-9.

${ }^{15}$ Clary, R. M; Sumrall, J. L; Rodgers, J. C, III; Wandersee, J. H. The Effects of Geographic Affiliation on Students' Perceptions, Awareness, and Responses to the 2010 Deepwater Horizon Oil Spill. J. Geosci. Educ. 2013, 61, 453-460.

${ }^{16}$ Lasker, G. A.; Mellor, K. E.; Mullins, M. L.; Nesmith, S. M.; Simcox, N. J. Social and Environmental Justice in the Chemistry Classroom. J. Chem. Educ. 2017, 94, 983-987.

${ }^{17}$ Bouillion, L. M.; Gomez, L. M. Connecting School and Community with Science Learning: Real World Problems and School-Community Partnerships as Contextual Scaffolds. J. Res. Sci. Tech. 2001, 38, 878898.

${ }^{18}$ Lasker, G. A.; Mellor, K. E.; Mullins, M. L.; Nesmith, S. M.; Simcox, N. J Social and Environmental Justice in the Chemistry Classroom. J. Chem. Educ. 2017, 94, 983-987.

${ }^{19}$ Davis, E. J.; Pauls, S.; Dick, J. Project-Based Learning in Undergraduate Environmental Chemistry Laboratory: Using EPA Methods To Guide Student Method Development for Pesticide Quantitation. $J$. Chem. Educ. 2017, 94, 451-457.

${ }^{20}$ Berger, M.; Goldfarb, J. L. Understanding Our Energy Footprint: Undergraduate Chemistry Laboratory Investigation of Environmental Impacts of Solid Fossil Fuel Wastes. J. Chem. Educ. 2017, 94, 1124-1128. 
${ }^{21}$ Wagner, C. S.; Roessner, J. D.; Bobb, K.; Klein, J. T.; Boyack, K. W.; Keyton, J.; Rafols, I.; Borner, K. Approaches to Understanding and Measuring Interdisciplinary Scientific Research (IDR): A Review of the Literature. J. Informetrics 2011, 5, 14-26.

${ }^{22}$ Rhoten, D.; Parker, A. Education: Risks and Rewards of an Interdisciplinary Research Path. Science 2004, 306, 2046.

${ }^{23}$ Cresswell, S. L.; Loughlin, W. A. An Interdisciplinary Guided Inquiry Laboratory for First Year Undergraduate Forensic Science Students. J. Chem. Educ. 2015, 92, 1730-1735.

${ }^{24}$ Rapp, T. L.; Phillips, S. R.; Dmochowski, I. J. Kinetics and Photochemistry of Ruthenium Bisbipyridine Diacetonitrile Complexes: An Interdisciplinary Inorganic and Physical Chemistry Laboratory Exercise. $J$. Chem. Educ. 2016, 93, 2101-2105.

${ }^{25}$ Monga, V.; Bussiere, G.; Crichton, P.; Daswani, S. Synthesis and Decomposition Kinetic Studies of Bis(lutidine)silver(I) Nitrate Complexes as an Interdisciplinary Undergraduate Chemistry Experiment. $J$. Chem. Educ. 2016, 93, 958-962.

${ }^{26}$ Cavalli, G.; Hamerton, I.; Lygo-Baker, S. What Are We Going To Do About a Problem Like Polymer Chemistry? Develop New Methods of Delivery to Improve Understanding of a Demanding Interdisciplinary Topic. Chem. Educ. Res. Practice 2015, 16, 293-301.

${ }^{27}$ Sumter, T. F.; Owens, P. M. An Approach to Teaching General Chemistry II that Highlights the Interdisciplinary Nature of Science. Biochem. Molec. Biol. Educ. 2011, 39, 110-116.

${ }^{28}$ Marks, P.; Levine, M. Synthesis of a Near-Infrared Emitting Squaraine Dye in an Undergraduate Organic Laboratory. J. Chem. Educ. 2012, 89, 1186-1189.

${ }^{29}$ Mako, T.; Levine, M. Synthesis of a Fluorescent Conjugated Polymer in the Undergraduate Organic Teaching Laboratory. J. Chem. Educ. 2013, 90, 1376-1379.

${ }^{30}$ Smaldone, R. A.; Forgan, R. S.; Furukawa, H.; Gassensmith, J. J.; Slawin, A. M. Z.; Yaghi, O. M.; Stoddart, J. F. Metal-Organic Frameworks from Edible Natural Products. Angew. Chem. Int. Ed. 2010, 49, $8630-8634$.

${ }^{31}$ Gassensmith, J. J.; Furukawa, H.; Smaldone, R. A.; Forgan, R. S.; Botros, Y. Y.; Yaghi, O. M.; Stoddart, J. F. Strong and Reversible Binding of Carbon Dioxide in a Green Metal-Organic Framework. J. Am. Chem. Soc. 2011, 133, 15312-15315.

${ }^{32}$ Wang, L.; Liang, X.-Y.; Chang, Z.-Y.; Ding, L.-S.; Zhang, S.; Li, B.-J. Effective Formaldehyde Capture by Green Cyclodextrin-Based Metal-Organic Framework. ACS Appl. Mater. Interfaces 2018, 10, 42-46.

${ }^{33}$ Abucafy, M. P.; Caetano, B. L.; Chiari-Andreo, B. G.; Fonseca-Santos, B.; do Santos, A. M.; Chorilli, M.; Chiavacci, L. A. Supramolecular Cyclodextrin-Based Metal-Organic Frameworks as Efficient Carrier for Anti-Inflammatory Drugs. Eur. J. Pharmaceutics Biopharmaceutics 2018, 127, 112-119.

${ }^{34}$ Han, S.; Wei, Y.; Grzybowski, B. A. A Metal-Organic Framework Stabilizes an Occluded Photocatalyst. Chem. - Eur. J. 2013, 19, 11194-11198.

${ }^{35}$ Smith, M. K.; Angle, S. R.; Northrop, B. H. Preparation and Analysis of Cyclodextrin-Based MetalOrganic Frameworks: Laboratory Experiments Adaptable for High School through Advanced Undergraduate Students. J. Chem. Educ. 2015, 92, 368-372.

${ }^{36}$ Rafatullah, M.; Sulaiman, O.; Hashim, R.; Ahmad, A. Adsorption of Methylene Blue on Low-Cost Adsorbents: A Review." J. Hazardous Mater. 2010, 177, 70-80.

${ }^{37}$ Berrios, M.; Martin, M. A.; Martin, A. Treatment of Pollutants in Wastewater: Adsorption of Methylene Blue onto Olive-Based Activated Carbon. J. Industrial Engin. Chem. 2012, 18, 780-784. 
${ }^{38}$ Hamed, M. M.; Ahmed, I. M.; Metwally, S. S. Adsorptive Removal of Methylene Blue as Organic Pollutant by Marble Dust as Eco-Friendly Sorbent. J. Industrial Engin. Chem. 2014, 20, 2370-2377.

39 Tucker, D.; Lu, Y.; Zhang, Q. From Mitochondrial Function to Neuroprotection-an Emerging Role for Methylene Blue. Molec. Neurobiol. 2017, 55, 5137-5153.

${ }^{40}$ Van der Sluis, P.; Hezemans, A. M. F.; Kroon, J. Crystallization of Low-Molecular-Weight Organic Compounds for X-Ray Crystallography. J. Appl. Crystallography 1989, 22, 340-344.

${ }^{41}$ Liu, B.; He, Y.; Han, L.; Singh, V.; Xu, X.; Guo, T.; Meng, F.; Xu, X.; York, P.; Liu, Z.; Zhang, J. Microwave-Assisted Rapid Synthesis of $\gamma$-Cyclodextrin Metal-Organic Frameworks for Size Control and Efficient Drug Loading. Crystal Growth Design 2017, 17, 1654-1660.

${ }^{42}$ Sha, J.-Q.; Wu, L.-H.; Li, S.-X.; Yang, X.-N.; Zhang, Y.; Zhang, Q.-N.; Zhu, P.-P. Synthesis and Structure of New Carbohydrate Metal-Organic Frameworks and Inclusion Complexes. J. Molec. Structure 2015, 1101, 14-20.

${ }^{43}$ Rafatullah, M.; Sulaiman, O.; Hashim, R.; Ahmad, A. Adsorption of Methylene Blue on Low-Cost Adsorbents: A Review." J. Hazardous Mater. 2010, 177, 70-80; DOI: 10.1016/j.jhazmat.2009.12.047.

${ }^{44}$ Paramelle, D.; Sadovoy, A.; Gorelik, S.; Free, P.; Hobley, J.; Fernig, D. G. A Rapid Method to Estimate the Concentration of Citrate Capped Silver Nanoparticles from UV-Visible Light Spectra. Analyst 2014, $139,4855-4861$.

${ }^{45}$ Iacovino, R.; Caso, J. V.; Di Donato, C.; Malgieri, G.; Palmieri, M.; Russo, L.; Isernia, C. Cyclodextrins as Complexing Agents: Preparation and Applications. Curr. Org. Chem. 2017, 21, 162-176.

${ }^{46}$ Biedermann, F.; Schneider, H.-J. Experimental Binding Energies in Supramolecular Complexes. Chem. Rev. 2016, 116, 5216-5300.

${ }^{47}$ Abualia, M.; Schroeder, L.; Garcia, M.; Daubenmire, P. L.; Wink, D. J.; Clark, Ginevra A. Connecting Protein Structure to Intermolecular Interactions: A Computer Modeling Laboratory. J. Chem. Educ. 2016, 93, 1353-1363.

${ }^{48}$ Debbert, S. L.; Hoh, B. D.; Dulak, D. J. Synthesis and Characterization of Calixarene Tetraethers: An Exercise in Supramolecular Chemistry for the Undergraduate Organic Laboratory. J. Chem. Educ. 2016, 93, 372-375.

${ }^{49}$ Pessine, F. B. T.; Calderini, A.; Alexandrino, G. L. Review: Cyclodextrin Inclusion Complexes Probed by NMR Techniques. Ed. Kim, D. Magnetic Resonance Spectroscopy 2012, 237-264.

${ }^{50}$ Popa, A.; Abenojar, E. C.; Vianna, A.; Buenviaje, C. Y. A.; Yang, J.; Pascual, C. B.; Samia, A. C. S. Fabrication of Metal Nanoparticle-Modified Screen Printed Carbon Electrodes for the Evaluation of Hydrogen Peroxide Content in Teeth Whitening Strips. J. Chem. Educ. 2015, 92, 1913-1917.

${ }^{51}$ Gonzalez-Sanchez, M.-I.; Gomez-Monedero, B.; Agrisuelas, J.; Valero, E. Recycling Metals from Spent Screen-Printed Electrodes While Learning the Fundamentals of Electrochemical Sensing. J. Chem. Educ. 2018, 95, 847-851.

${ }^{52}$ Izutani, C.; Fukagawa, D.; Miyasita, M.; Ito, M.; Sugimura, N.; Aoyama, R.; Gotoh, T.; Shibue, T.; Igarashi, Y.; Oshio, H. The Materials Characterization Central Laboratory: An Open-Ended Laboratory Program for Fourth-Year Undergraduate and Graduate Students. J. Chem. Educ. 2016, 93, 1667-1670. 